\title{
Rancangan Konstruksi Kapal Penangkap Ikan 60 GT Untuk Nelayan Pelabuhan Perikanan Nusantara Karangantu Kota Serang
}

\author{
Iswadi Nur $^{1 *}$, Purwo Joko Suranto ${ }^{1}$, Amir Marasabessy ${ }^{1}$ \\ ${ }^{1}$ Program Studi Teknik Perkapalan Fakultas Teknik UPN Veteran Jakarta \\ *Korespondensi penulis: iswadinur62@gmail.com
}

\begin{abstract}
Abstrak. Rancangan perhitungan konstruksi kapal penangkap ikan mengacu kepada regulasi klas yaitu Biro Klasifikasi Indonesia (BKI) khusus untuk kapal perikanan yang terbuat dari bahan baja. Ukuran pokok kapal adalah Loa $=25,45 \mathrm{~m}, \mathrm{~B}=5,40$ $\mathrm{m}, \mathrm{H}=2,20 \mathrm{~m}$, dan $\mathrm{T}=1,60 \mathrm{~m}$, alat tangkap pancing yang ramah lingkungan, kecepatan 12,5 knots. Hasil rancangan konstruksi dimaksud dapat dijamin baik dan aman disebabkan perhitungannya mengacu kepada standar klas (BKI). Apalagi tetap mempertahan bagian konstruksi seperti bilge keel, fender dan penebalan ukuran tebal pelat kubu bagian paling atas dan top plate kubu. Bilge keel berfungsi untuk memperlambat periode oleng. Perlambatan periode oleng sangat bermanfaat agar ikan hasil tangkapan yang berada pada palka ikan (cold storage) tidak rusak akibat goncangan atau keolengan kapal. Fender berfungsi untuk melindungi benturan badan kapal dengan dermaga saat berlabuh, serta penebalan bagian paling atas kubu dan top plate kubu berfungsi untuk menambah ketegaran konstruksi kubu sebagai penahan atau pelindung awak kapal saat mancing. Terdapat fungsi lainnya dari ketiga bagian konstruksi tersebut yaitu untuk menambah modulus penampang konstruksi melintang kapal. Penelitian ini dimaksudkan sebagai upaya untuk membantu para nelayan PPN Karangantu agar dapat mengetahui dan memahami kosntruksi kapal perikanan yang terbuat dari bahan baja. Selain itu dapat memotivasi kelompok nelayan Karangantu agar mempunyai armada kapal ikan yang besar dan layak beroperasi pada perairan Samudera (ZEE) dan perairan internasional yang memiliki rumpon berbagai jenis ikan. Jika kelompok nelayan PPN Karangantu memiliki armada kapal penangkap ikan berukuran besar dengan jumlah yang banyak, berdampak kepada kinerja peningkatan produksi perikanan tangkap PPN Karangantu.
\end{abstract}

Kata kunci: konstruksi; nelayan; PPN Karangantu.

\section{PENDAHULUAN}

Peraturan Menteri Kelautan dan Perikanan Republik Indonesia Nomor Per. 08/Men/2012 tentang Kepelabuhanan Perikanan di Indonesia terbagi dalam 4 kelas, yaitu Pelabuhan Perikanan Samudera (PPS), Pelabuhan Perikanan Nusantara (PPN), Pelabuhan Perikanan Pantai (PPP), Pangkalan Pendaratan Ikan (PPI). Jumlah masing-masing jenis pelabuhan perikanan adalah PPS berjumlah 6 buah, PPN berjumlah 15 buah, PPP berjumlah sekitar 44 buah, dan selebihnya PPI berjumlah 937 buah [1, 2]. Pelabuhan Perikanan Samudera jumlahnya masih sangat sedikit dan tidak sebanding dengan luas wilayah lautan Indonesia. Jumlah Pelabuhan Perikanan Samudera semestinya ditingkatkan untuk meningkatkan jumlah produksi perikanan tangkap di Indonesia. Disamping itu untuk meningkatkan produksi perikanan tangkap juga dapat dilakukan dengan meningkatkan kinerja Pelabuhan Perikanan Nusantara dengan cara meningkatkan jumlah armada kapal perikanan yang berukuran relatif besar [3]. Pada penelitian ini diambil contoh PPN Karangantu Kota Serang yang memiliki potensi untuk ditingkatkan kinerjanya melalui penambahan jumlah armada kapal penangkap ikan yang berukuran besar. Dengan alasan PPN Karangantu memiliki jumlah armada kapal penangkap ikan yang berukuran besar masih sangat sedikit, dan memiliki wilayah perairan relatif luas sebagai tempat beroperasinya armada kapal perikanan bagi para nelayannya [4]. Wilayah perairan PPN Karangantu di sebelah Utara adalah Laut Jawa atau Selat Sunda, dan di sebelah Barat 
tersambung dengan wilayah perairan Samudera Indonesia. Wilayah perairan tersebut dimungkinkan dapat dijadikan wilayah operasi kapal nelayannya jika ukuran kapal penangkap ikannya berukuran besar. Alasan lainnya adalah PPN Karangantu relatif dekat dengan Ibukota Jakarta sebagai tempat pemasaran produksi perikanan tangkap. Peningkatan kinerja pelabuhan perikanan merupakan upaya untuk mewujudkan implementasi dari Peraturan Presiden No.26/2012 yang berhubungan dengan cetak biru pengembangan sistem logistik nasional serta mewujudkan Program Peningkatan Kehidupan Nelayan (PKN) yang sebelumnya telah ditetapkan dan Kepres Nomor 10 tahun 2011. Hasil akhir dari peningkatan kinerja pelabuhan perikanan adalah meningkatkan produksi perikanan tangkap salah satu cara melalui peningkatan jumlah armada kapal perikanan yang berukuran relatif besar.

Pengembangan pelabuhan perikanan di semua kelas sangat penting sebagai upaya untuk menciptakan pusat-pusat pertumbuhan ekonomi yang bertumpu pada komoditas kelautan dan perikanan. Perbaikan kinerja PPN berdampak kepada pengembangan potensi ekonomi daerah sekitarnya seperti industri pariwisata, industri perikanan, peluang ekspor, pada akhirnya menjadi peluang penyerapan tenaga kerja. Karakteristik/kelas pelabuhan sesuai Keputusan Menteri KKP no 16 Th. 2006 untuk PPS dan PPN seperti tabel.1 di bawah ini.

TABEL 1. Kriteria Pelabuhaa Perikanan PPS dan PPN [5].

\begin{tabular}{|c|l|l|l|}
\hline No & Kriteria Pelabuhan Perikanan & \multicolumn{1}{|c|}{ PPS } & \multicolumn{1}{|c|}{ PPN } \\
\hline 1 & $\begin{array}{l}\text { Daerah operasional kapal ikan } \\
\text { yang dilayani }\end{array}$ & $\begin{array}{l}\text { Wilayah laut teritorial, Zona } \\
\text { Ekonomi Ekslusif (ZEEI) dan } \\
\text { perairan internasional }\end{array}$ & $\begin{array}{l}\text { Perairan ZEEI dan laut } \\
\text { territorial }\end{array}$ \\
\hline 2 & Fasilitas tambat/labuh kapal & $>60 \mathrm{GT}$ & $30-60 \mathrm{GT}$ \\
\hline 3 & $\begin{array}{l}\text { Panjang dermaga dan } \\
\text { Kedalaman kolam }\end{array}$ & $>300 \mathrm{~m}$ dan $>3 \mathrm{~m}$ & $150-300 \mathrm{~m}$ dan $>3 \mathrm{~m}$ \\
\hline 4 & Kapasitas menampung Kapal & $\begin{array}{l}>6000 \mathrm{GT} \\
\text { (ekivalen dengan 100 buah kapal } \\
\text { berukuran 60 GT) }\end{array}$ & $\begin{array}{l}>2250 \mathrm{GT} \\
\text { (ekivalen dengan 75 buah } \\
\text { kapal berukuran 30 GT) }\end{array}$ \\
\hline 5 & Volume ikan yang didaratkan & Rata-rata 60 ton/hari & Rata-rata 30 ton/hari \\
\hline 6 & Ekspor ikan & Ya & Ya \\
\hline 7 & Luas lahan & $>30 \mathrm{Ha}$ & 15-30 Ha \\
\hline 8 & $\begin{array}{l}\text { Fasilitas pembinaan mutu hasil } \\
\text { perikanan }\end{array}$ & Ada & Ada/Tidak \\
\hline 9 & $\begin{array}{l}\text { Tata ruang (zonasi) pengolahan/ } \\
\text { pengembangan industri } \\
\text { perikanan }\end{array}$ & Ada & Ada \\
\hline
\end{tabular}

Sesuai tabel 1, maka ukuran kapal perikanan yang layak beroperasi pada Pelabuhan Perikanan Samudera dan Pelabuhan Perikanan Nusantara sebaiknya berukuran $30-60$ GT, dimana pada penelitian ini mengambil ukuran 60 GT [6]. Kapal perikanan yang berukuran 60 GT layak beroperasi pada daerah perairan lebih dari 50 mil laut dari garis pantai seperti pada wlayah perairan ZEE maupun wilayah perairan internasional, dimana arus dan gelombangnya relatif besar. Kapal penangkap ikan dimaksud sebaiknya menggunakan alat tangkap jenis pancing yang ramah lingungan [7]. Sehingga pada penelitian ini menitik beratkan pada konstruksi kapal yang baik dan aman. Rancangan konstruksi kapal perikanan dimaksud harus mampu menahan gaya-gaya yang bekerja pada lambung kapal baik gaya-gaya yang berasal dari berat konstruksi kapal sendiri maupun gaya-gaya yang berasal dari luar kapal, dan memiliki stabilitas yang baik [8].

Berdasarkan Peraturan Menteri Kelautan dan Perikanan nomor: Per.20/Permen-KP/2014, tanggal 16 Mei 2014, pelabuhan perikanan sekelas PPN Karangantu mempunyai kedudukan sebagai Unit Pelaksana Teknis (UPT) dibidang pelabuhan perikanan yang berada di bawah Direktur Jenderal Perikanan Tangkap (DJPT) Kementerian Kelautan dan Perikanan (KKP). Sehingga PPN Karangantu memiliki tugas pokok untuk memfasilitasi produksi dan pemasaran hasil perikanan tangkap yang berada di wilayahnya. PPN Karangantu melakukan pengawasan dan pemanfaatan sumberdaya ikan untuk 
pelestariannya, dan kelancaran kegiatan kapal perikanan, serta pelayanan kesyahbandaran di pelabuhan perikanan [9].

Fungsi pelabuhan sekelas PPN Karangantu berdasarkan Peraturan Menteri Kelautan dan Perikanan Nomor: PER.08/MEN/2012 tentang Kepelabuhanan. Dalam rangka melaksanakan kegiatan pelabuhan perikanan memiliki dua fungsi yaitu fungsi pemerintahan dan fungsi pengusahaan. Fungsi pemerintahan merupakan fungsi untuk melaksanakan pengaturan, pembinaan, pengendalian, pengawasan, serta keamanan dan keselamatan operasional kapal perikanan di pelabuhan perikanan.

Dengan demikian pelabuhan perikanan mempunyai fungsi untuk memberikan bantuan dalam hal pembinaan bantuan teknologi terkait pengadaan, pemeliharaan kapal perikanan kepada para nelayannya yang berada di wilayahnya. Sehingga bagi sivitas akademika yang berada pada lembaga pendidikan tinggi dapat memberikan bantuan pemikiran tentang pengembangan armada kapal perikanan.

TABEL 2. Kunjungan Kapal Perikanan di PPN Karangantu [9].

\begin{tabular}{|c|c|c|c|}
\hline No & Katagori Kapal (GT) & Frekuensi Kunjungan Kapal (kali) & Pendaratan Tangkapan (kali) \\
\hline 1 & $<5 \mathrm{GT}$ & 386 & 386 \\
\hline 2 & $5-10 \mathrm{GT}$ & 3 & 3 \\
\hline 3 & $10-20 \mathrm{GT}$ & 3 & 3 \\
\hline 4 & $20-30 \mathrm{GT}$ & 3 & 3 \\
\hline
\end{tabular}

Berdasarkan tabel 2 yang merupakan hasil dari data dan informasi kunjungan kapal perikanan di PPN Karangantu pada bulan Juni 2019, armada kapal perikanan PPN Karangantu sebagian besar adalah kapal-kapal penangkap ikan yang berukuran dibawah 5 GT [4]. Jumlah kunjungan kapal penangkap ikan yang berukuran besar sangat sedikit, sehingga perlu upaya untuk meningkatkan jumlah aemada kapal perikanan yang berukuran besar. Dengan demikian diperlukan bantuan teknologi kepada para nelayan PPN Karangantu sebagai contoh rancangan konstruksi kapal penangkap ikan yang berukuran $60 \mathrm{GT}$.

Tujuan penelitian adalah selain untuk mendapatkan ukuran konstruksi kapal penangkap ikan 60 GT berdasarkan standar Biro Klasifikasi Indonesia (BKI), agar dapat dipastikan kapal tersebut baik dan aman jika berlayar pada wilayah laut teritorial, zona ekonomi eklusif (ZEE) dan perairan internasional. juga untuk memberikan masukan kepada khalayak yaitu model konstruksi kapal penangkap ikan 60 GT khususnya untuk para nelayan di PPN Karangantu.

\section{TINJAUAN PUSTAKA}

\section{Kekuatan Konstruksi Kapal Perikanan}

Konstruksi kapal perikanan sama halnya dengan perhitungan konstruksi kapal-kapal niaga [9]. Indikatornya adalah kekuatan memanjang kapal yaitu besarnya tegangan yang terjadi pada bagian tengah konstruksi kapal, dimana nilai tegangannya harus lebih kecil dari tegangan ijin baja kapal.

\section{Tegangan Tarik dan Tegangan Tekan}

Tegangan yang paling berbahaya saat kapal berlayar terbagi pada dua kondisi yaitu pertama jika kapal berada pada dua puncak gelombang (sagging) dan yang kedua kapal berada pada satu puncak gelombang (hogging). Pada saat kondisi hogging pelat dasar daerah tengah kapal mengalami tegangan tekan, dan pelat geladak daerah tengah kapal mengalami tegangan tarik. Sebaliknya pada saat kondisi sagging pelat dasar mengalami tegangan tarik, dan pelat geladak mengalami tegangan tekan.

Besarnya tegangan yang dialami oleh kapal dapat dihitung dari momen maksimum yang dialami lambung kapal saat kapal berlayar dibagi dengan modulus penampang bagian konstruksi tengah kapal [9]. 


\section{Modulus Penampang}

Besar dan kecilnya modulus penampang tersebut sangat tergantung dari besar dan kecilnya momen inersia dari konstruksi tengah kapal.

\section{Ukurann Konstruksi}

Untuk mendapatkan ukuran konstruksi kapal terlebih dahulu dihitung rancangan beban konstruksi yang perhitunganya berdasarkan rumus empiris yang ditentukan oleh standar BKI. Rumus empiris beban rancangan konstruksi kapal tersebut didasarkan pada ukuran pokok kapal dengan mempertimbangkan beberapa faktor seperti faktor distribusi beban laut baik yang berasal dari muatan kapal maupun dari besarnya tekanan air laut, faktor korosi, faktor kekuatan material.

\section{Distribusi Beban}

Distribusi beban laut pada saat kapal berlayar di lautan terdapat beberapa gaya luar yang bekerja pada badan kapal baik pada daerah dasar dan sisi kapal yang terendam di bawah garis air maupun pada daerah geladak kapal. Gaya-gaya yang bekerja pada badan kapal tersebut dapat ditinjau menjadi tiga bagian besar yaitu daerah buritan (After Peak) disingkat A, daerah tengah kapal (Middle Ship) disingkat M, dan daerah haluan kapal (Fore Peak) disingkat dengan F.

\section{METODE PERHITUNGAN}

\section{Faktor distribusi beban}

Faktor distribusi beban untuk perhitungan konstruksi kapal perikanan sebagaimana dijelaskan pada tabel 3 .

TABEL 3. Distibution factor for sea loads on ship's side and weather decks [9].

\begin{tabular}{|c|c|c|c|}
\hline \multicolumn{2}{|r|}{ Range } & Factor $C_{D}$ & Factor $C_{F}$ \\
\hline A & $0 \leq \frac{x}{L} \leq 0.2$ & $1.2-\frac{X}{L}$ & $1.0+\frac{5}{C B}\left(0.2-\frac{x}{L}\right)$ \\
\hline M & $0.2 \leq \frac{\pi}{L} \leq 0.7$ & 1.0 & 1.0 \\
\hline $\mathrm{F}$ & $0.7 \leq \frac{x}{L} \leq 1.0$ & $\begin{array}{c}1,0+\frac{c}{g}\left(\frac{x}{L}-0.7\right) \\
\mathrm{c}=0.15 \mathrm{~L}-10 \\
\text { where: } \mathrm{L} \min =100 \mathrm{~m} \\
\mathrm{~L}_{\max }=250 \mathrm{~m}\end{array}$ & $1.0+\frac{20}{C B}\left(\frac{x}{L}-0.7\right)^{2}$ \\
\hline \multicolumn{4}{|c|}{$\begin{array}{l}\text { Within the range A the ratio } \frac{x}{L} \text { need not be taken less then } 0,1 \text {, within the rang } \mathrm{F} \text { the ratio } \frac{\alpha}{L} \text { need not be } \\
\text { taken greater than } 0.93\end{array}$} \\
\hline
\end{tabular}

\section{Koreksi Bahan Bajan}

Dalam perhitungan konstruksi kapal berbahan baja harus dikoreksi oleh tegangan luluh $(\mathrm{ReH})$ yang terkait dengan faktor keamanan bahan. Hal ini disebabkan oleh kondisi nyata di lautan yaitu pada saat kapal berlayar pasti mengalami gaya luar seperti arus gelombang air laut yang dapat mempengaruhi kekuatan konstruksi memanjang kapal. Menurut standar Biro Klasifikasi Indonesia (BKI) Bab 2, Bagian B. 2 tentang baja konstruksi lambung kekuatan tinggi, ditentukan dengan harga tegangan luluh $(\mathrm{ReH})$ dan faktor keamanan (k), sebagaimana diperlihatkan pada tabel 4.

\section{Marjin Korosi}

Disamping itu dalam perhitungan beban rancangan konstruksi kapal wajib mempertimbangkan faktor korosi dan disebut dengan marjin korosi minimum. Badan kapal yang terbuat dari baja pasti mengalami korosi sehingga perlu dikoreksi dengan konstanta korosi. Korosi yang terjadi terbagi dua yaitu korosi yang terjadi pada daerah badan kapal di bawah garis air disebut dengan korosi elektrolisa sedangkan korosi yang terjadi pada bagian di atas garis air disebut dengan korosi oksidasi. Marjin korosi minimum dari bahan baja kapal harus sesuai dengan standar Biro Klasifikasi Indonesia (BKI) Bab 3, Bagian K. 1, tentang marjin korosi $\left(\mathrm{t}_{\mathrm{K}}\right)$ tidak boleh kurang dari $\mathrm{t}_{\mathrm{K}}$ yang terdapat pada tabel 3.6, sebagaimana ditampilkan pada tabel 5. 
TABEL 4. Faktor Bahan [9].

\begin{tabular}{|c|c|}
\hline $\mathbf{R e H}\left(\mathbf{N} / \mathbf{m m}^{\mathbf{2}}\right)$ & $\mathbf{k}$ \\
\hline 265 & 0.91 \\
\hline 315 & 0.78 \\
\hline 355 & 0.72 \\
\hline 390 & 0.66 \\
\hline
\end{tabular}

TABEL 5: Marjin Korosi Minimum [9].

\begin{tabular}{|c|c|}
\hline Daerah & $\mathrm{t}_{\mathrm{K}} \min (\mathrm{mm})$ \\
\hline $\begin{array}{c}\text { Dalam tangki balas dimana geladak cuaca menjadi atap tangki, } 1.5 \mathrm{~m} \text { di bawah atap } \\
\text { tangki }\end{array}$ & 2.5 \\
\hline $\begin{array}{l}\text { Dalam tangki minyak muatan dimana geladak cuaca menjadi atapnya, } 1.5 \mathrm{~m} \text { di bawah } \\
\text { atap tangki. Bagian horizontal dalam tangki minyak muatan dan tangki bahan bakar. }\end{array}$ & 2.0 \\
\hline Pelat geladak di bawah rumah geladak yang dipasang secara elastis & 3.0 \\
\hline \multicolumn{2}{|l|}{$\mathrm{t}_{\mathrm{K}}=2.5$ untuk semua konstruksi di dalam tangki sayap atas kapal curah. } \\
\hline terbuka terhadap operasi cengkram dan diberi notasi G, maka marjin kor & 5 \\
\hline
\end{tabular}

\section{HASIL DAN PEMBAHASAN}

\section{Perhitungan Konstruksi Kapal.}

Dimana hasil perhitungan dari konstruksi kapal perikanan untuk ukuran 60 GT tidak boleh kurang dari standar yang telah ditetapkan oleh BKI sebagaimana diperlihatkan pada tabel 6.

TABEL 6. Ukuran konstruksi berdasarkan standar BKI [9].

\begin{tabular}{|c|c|c|}
\hline No. & Daerah Konstruksi & Ukuran Konstruksi \\
\hline \multirow[t]{9}{*}{1.} & Konstruksi Dasar & \\
\hline & Pelat dasar (after peak, middle body, fore peak) & Tebal $7 \mathrm{~mm}$ \\
\hline & Pelat lunas datar $0.7 \mathrm{~L}$ & Lebar $=930 \mathrm{~mm}$, Tebal $=9 \mathrm{~mm}$ \\
\hline & Pelat lunas datar $0.15 \mathrm{~L}$ ujung haluan dan buritan & Lebar $=930 \mathrm{~mm}$, Tebal $=8 \mathrm{~mm}$ \\
\hline & Pelat lajur bilga & Lebar $=930 \mathrm{~mm}$, Tebal $=7 \mathrm{~mm}$ \\
\hline & $\begin{array}{l}\text { Alas tunggal ceruk haluan } \\
\text { Top plate }\end{array}$ & $\begin{array}{l}\text { Tinggi } 252 \mathrm{~mm} \text { tebal } 6 \mathrm{~mm} \\
40 \times 8 \mathrm{~mm}\end{array}$ \\
\hline & Alas ganda Penumpu Tengah & Tinggi $(\mathrm{h})=600 \mathrm{~mm}$, tebal $=7 \mathrm{~mm}$ \\
\hline & Wrang & Tinggi $(\mathrm{h})=600 \mathrm{~mm}$, tebal $=5 \mathrm{~mm}$ \\
\hline & Pelat dasar dalam & Tebal $=5 \mathrm{~mm}$ \\
\hline \multirow[t]{14}{*}{2.} & Konstruksi Sisi & \\
\hline & Pelat sisi 0.3 L After Peak & Tebal $=8 \mathrm{~mm}$ \\
\hline & Pelat sisi 0.4 L Midship & Tebal $=7 \mathrm{~mm}$ \\
\hline & Pelat sisi 0.3 L Fore Peak & Tebal $=8 \mathrm{~mm}$ \\
\hline & Pelat lajur atas $0.3 \mathrm{~L}$ After Peak & Tebal $=8 \mathrm{~mm}$ \\
\hline & Pelat lajur atas $0.4 \mathrm{~L}$ Mid ship & Tebal $=7 \mathrm{~mm}$ \\
\hline & Pelat lajur atas $0.3 \mathrm{~L}$ After Peak & Tebal $=8 \mathrm{~mm}$ \\
\hline & Pelat kubu kubu & Tebal $=5 \mathrm{~mm}$ \\
\hline & Main frame After Peak & Ukuruan profil $\mathrm{L}=65 \times 50 \times 5$ \\
\hline & Main frame Midship & Ukuruan profil $\mathrm{L}=60 \times 40 \times 6$ \\
\hline & Main frame Fore Peak & Ukuruan profil $\mathrm{L}=75 \times 55 \times 5$ \\
\hline & Web frame After Peak & Ukuruan profil $\mathrm{I}=100 \times 8$ \\
\hline & Web frame Midship & Ukuruan profil $\mathrm{I}=100 \times 6$ \\
\hline & Web frame Fore Peak & Ukuruan profil $\mathrm{I}=120 \times 6$ \\
\hline \multirow[t]{8}{*}{3.} & Konstruksi Geladak & \\
\hline & Pelat Geladak & Tebal $=6.00 \mathrm{~mm}$ \\
\hline & Deck Beam After Peak & Ukuruan profil $\mathrm{L}=75 \times 50 \times 5$ \\
\hline & Deck Beam Midship & Ukuruan profil $\mathrm{L}=70 \times 50 \times 5$ \\
\hline & Deck Beam Fore Peak & Ukuruan profil $\mathrm{L}=65 \times 5 \times 7$ \\
\hline & Deck Transverse After Peak & Ukuruan profil $\mathrm{I}=120 \times 8$ \\
\hline & Deck Transverse Midship & Ukuruan profil $\mathrm{I}=100 \times 8$ \\
\hline & Deck Transverse Fore Peak & Ukuruan profil I $=140 \times 7$ \\
\hline \multirow[t]{3}{*}{4.} & Sekat & \\
\hline & Sekat tubrukan & Jarak $3.10 \mathrm{~m}$ \\
\hline & Sekat Tubrukan dan lainnya & Tebal $=6.00 \mathrm{~mm}$ \\
\hline
\end{tabular}




\begin{tabular}{|c|l|l|}
\hline 5. & Bangunan Atas & \\
\hline & Pelat sisi & Tebal $=6.00 \mathrm{~mm}$ \\
\hline & Pelat geladak & Tebal $=6.00 \mathrm{~mm}$ \\
\hline & Main frame & Ukuruan profil $\mathrm{L}=60 \times 50 \times 5$ \\
\hline & Web frame & Ukuruan profil $\mathrm{I}=100 \times 8$ \\
\hline
\end{tabular}

Ada beberapa bagian konstruksi yang tetap dipertahankan ukurannya serta ada juga yang ditambah ukurannya seperti bagian konstruksi bilge keel dan fender jarang dipasang, tetapi pada penelitian ini tetap terpasang. Ukuran bagian konstruksi bilge keel terdiri dari double plate $=100 \times 10 \mathrm{~mm}$, bilge plate $=120 \times 10 \mathrm{~mm}$ dan round bar 14 $\mathrm{mm}$. Bilge keel berfungsi untuk memperlambat periode oleng. Perlambatan periode oleng sangat bermanfaat agar ikan hasil tangkapan yang berada pada palka ikan (cold storage) tidak rusak akibat goncangan atau keolengan kapal. Fender terbuat dari round bar plate dengan ukuran diameter $180 \mathrm{~mm}$ dan tebal $10 \mathrm{~mm}$, fender berfungsi untuk melindungi benturan badan kapal dengan dermaga saat berlabuh. Penebalan ukuran tebal pelat bagian paling atas kubu yaitu $100 \times 10 \mathrm{~mm}$ dan top plate kubu $50 \times 10 \mathrm{~mm}$. Penebalan pelat tersebut berfungsi untuk menambah ketegaran konstruksi kubu sebagai penahan atau pelindung awak kapal saat mancing. Fungsi lainnya dari ketiga bagian konstruksi tersebut adalah untuk menambah modulus penampang konstruksi melintang kapal karena ketiga bagian konstruksi tersebut menjadi bagian dari konstruksi tengah kapal sebagaimana terlihat pada gambar 1. Nilai modulus penampang melintang didapat dari momen inersia total dibagi dengan titik berat.

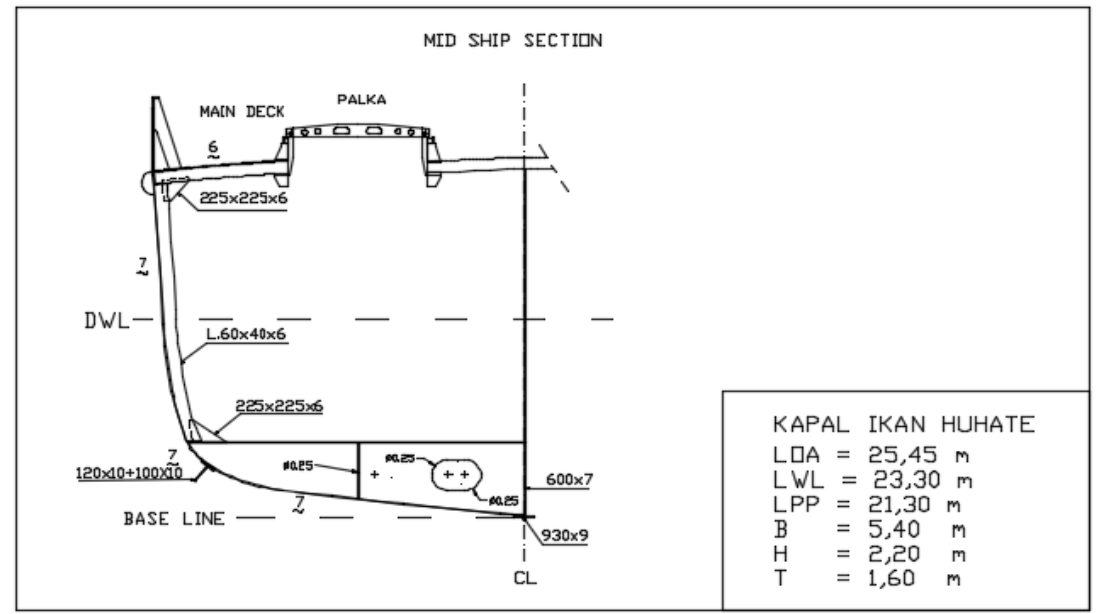

GAMBAR 1. Mid ship section.

\section{Perhitungan Volume Kapal dan Rencana Umum}

- Perhitungan Volume Kapal

Volume kotor ruangan (gross tonnage) dihitung dengan metode yang ditetapkan oleh Dirjen Perhubungan Laut. Metode perhitungan ini merupakan pengukuran yang digunakan di dalam negeri. Perhitungan ini sesuai dengan ketentuan dan peraturan menurut Keputusan Dirjen Perla No. PY.67/1/16-02, adapun rumus tersebut adalah sebagai berikut:

Volume Kapal $=0.25 \times$ V (GT)

Volume ruangan di bawah geladak $=\mathrm{L} \times \mathrm{B} \times \mathrm{D} \times \mathrm{f}$, dimana $\mathrm{Lpp}=21.3 \mathrm{~m}, \mathrm{~B}=5.40 \mathrm{~m}, \mathrm{D}$ $=2.2 \mathrm{~m}, \mathrm{f}=0.70-0.85$ diambil 0,70

Volume ruangan dibawah geladak $=21.3 \times 5.40 \times 2.2 \times 0.70=177.13 \mathrm{~m}^{3}$

Volume ruangan di atas geladak $=7 \mathrm{~m} \times 3.80 \mathrm{~m} \times 2.5 \mathrm{~m}=66.5 \mathrm{~m}^{3}$

Total Volume Kotor Ruangan $(\mathrm{V})=177.13 \mathrm{~m}^{3}+66.5 \mathrm{~m}^{3}=243.63 \mathrm{~m}^{3}$

$\mathrm{V}=0.25 \times \mathrm{V}$ (dalam satuan GT)

$\mathrm{V}=0.25 \times 243.63 \mathrm{~m}^{3}=60.90 \mathrm{GT}$ 
- Gambar Rencana Umum

Adapun gambar dari rencana umum kapal penangkap ikan tersebut, sebagaimana digambarkan pada gambar 2 .

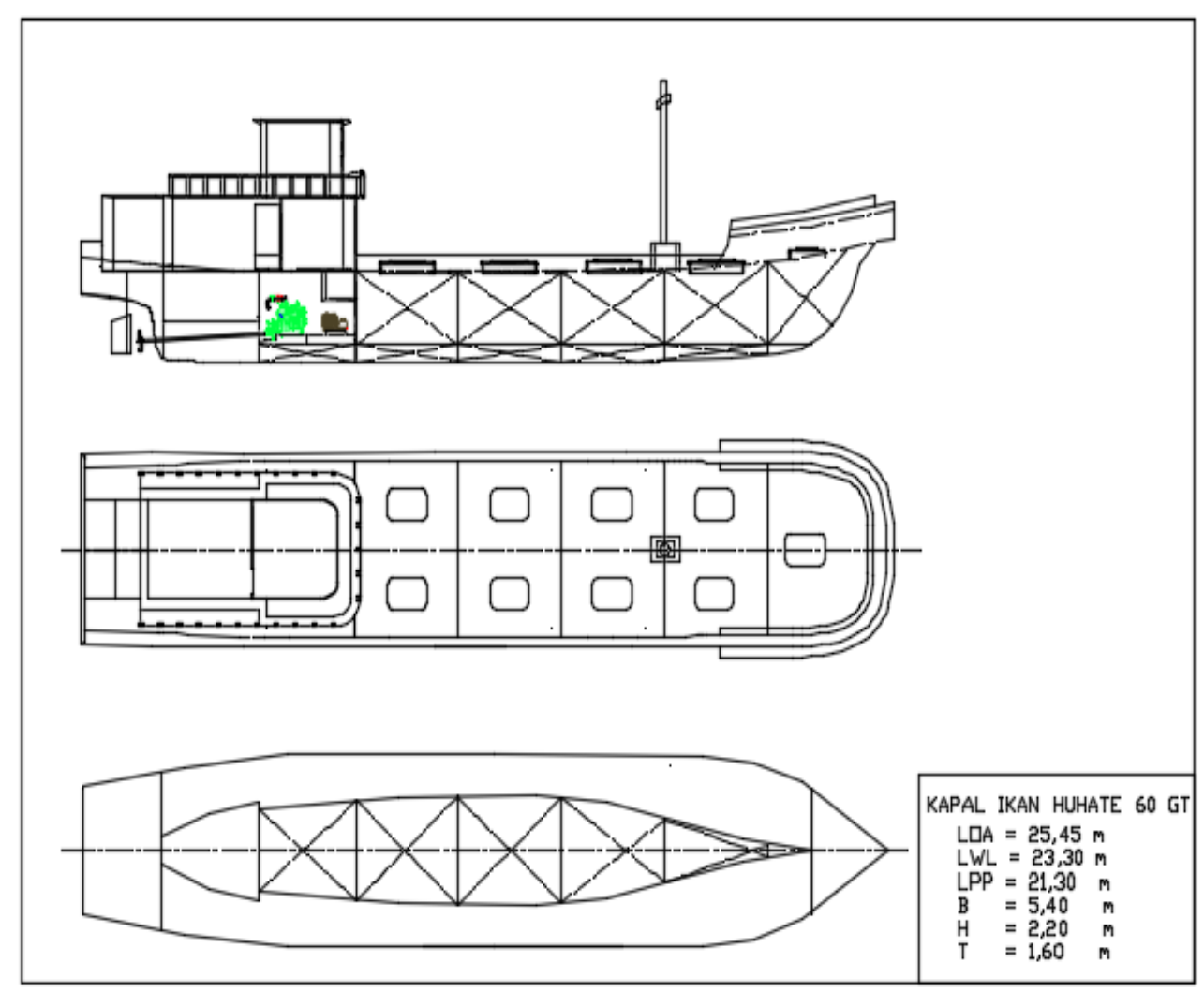

GAMBAR 2. Rencana umum

\section{KESIMPULAN}

Kesimpulan berupa spesifikasi hasil rancangan konstruksi kapal penangkap ikan 60 GT untuk nelayan pelabuhan perikanan nusantara karangantu kota serang, pertama, rancangan konstruksi kapal penangkap ikan memiliki ukuran pokok Loa $=25.45$ $\mathrm{m}, \mathrm{B}=5.40 \mathrm{~m}, \mathrm{H}=2.20 \mathrm{~m}$, dan $\mathrm{T}=1.60 \mathrm{~m}$, alat tangkap pancing yang ramah lingkunan, kecepatan 12.5 knots, volume 60 GT. Kedua, ukuran konstruksi kapal penangkap ikan berupa pelat lunas datar lebar $=930 \mathrm{~mm}$, tebal $=9 \mathrm{~mm}$, pelat dasar $7 \mathrm{~mm}$, pelat lajur bilga lebar $=930 \mathrm{~mm}$, tebal $7 \mathrm{~mm}$, pelat sisi $7 \mathrm{~mm}$, pelat lajur atas $7 \mathrm{~mm}$, pelat kubu 5 $\mathrm{mm}$, tinggi dasar ganda $=600 \mathrm{~mm}$, tebal $=0.7 \mathrm{~mm}$, pelat dasar dalam $=5 \mathrm{~mm}$, pelat geladak $=6 \mathrm{~mm}$, gading-gading utama $=$ profil L $60 \times 40 \times 6$, gading-gading besar $=$ profil I $100 \times 6 \mathrm{~mm}$, balok geladak = profil $\mathrm{L} 70 \times 50 \times 5 \mathrm{~mm}$, pelintang geladak $=$ profil I $100 \times 8 \mathrm{~mm}$.

\section{DAFTAR PUSTAKA}

[1] Peraturan Menteri Kelautan dan Perikanan Republik Indonesia Nomor Per. 08/Men/2012 Tentang Kepelabuhanan Perikanan. Jakarta: Kementerian Kelautan dan Perikanan, 2012.

[2] Kementerian Kelautan dan Perikanan, Pusat Informasi Pelabuhan Perikanan (PPIP), April 2015.

[3] Iswadi Nur dkk (2018), Design of Fishing Boat for Pelabuhanratu Fishermen as One of Effort to Increase Production of Capture Fisheries, IOP Conf.Series Journal 
of Physics Conf, 962 (2018)012009, doi 10.1088/1742-6596/962/i/2009, Copyright (C) 2018 Elsevier B.V. All right reversed, Scopus.

[4] Kementerian Kelautan dan Perikanan (2019), Profil Pelabuhan PPN Karangantu, www.kkp.go.id.

Tribun, Kementrian Kelautan Dan Perikanan Soroti Pengembangan budi Daya Laut, Selasa 3 Desember 2013

[5] EDI, Pramudya, et al. Analisis Efisiensi Pelabuhan Perikanan dean Strategi Pengembangan (Pokok Bahasan Pelabuhan Perikanan Ssmudera Cilacap)*) Efficiency Analysis and Development Strategy of Cilacap Fishing Port. Jurnal Pasir Laut, 2006, 2.1: 64-78.

[6] Peraturan Menteri Kelautan Dan Perikanan nomor: Per.16/Men/2006, Tentang Pelabuhan Perikanan.

[7] Peraturan Menteri Kelautan dan Perikanan nomor 2 tahun 2015, tentang Larangan Penggunaan Alat Penangkap Ikan (API) Pukat Hela (Trawl) dan Pulat Tarik (Seine Nets) di Wilayah Pengelolaan Perikanan Negara Republik Indonesia.

[8] IMO, Intact Stability Code, Intact Stability for All Types of Ships Covered by IMO Instruments. London, UK: IMO.

[9] Biro Klasifikasi Indonesia (2003), Rules for The Classification and Construction of Seagoing Steel Ships, Rules for Fishing Vessels, Biro Klasifikasi Indonesia Head Office, Jakarta. 